\title{
Emulating Atlantic overturning strength for low emission scenarios: consequences for sea-level rise along the North American east coast
}

\author{
C. F. Schleussner ${ }^{1,2}$, K. Frieler ${ }^{1}$, M. Meinshausen ${ }^{1,3}$, J. Yin ${ }^{4}$, and A. Levermannn ${ }^{1,2}$ \\ ${ }^{1}$ Potsdam Institute for Climate Impact Research, Telegrafenberg A62, 14473 Potsdam, Germany \\ ${ }^{2}$ Physics Institute, Potsdam University, Potsdam, Germany \\ ${ }^{3}$ School of Earth Sciences, University of Melbourne, Victoria, Australia \\ ${ }^{4}$ Department of Geosciences, University of Arizona, Tucson, AZ 85721, USA
}

Received: 3 December 2010 - Published in Earth Syst. Dynam. Discuss.: 10 December 2010

Revised: 25 August 2011 - Accepted: 13 September 2011 - Published: 28 September 2011

\begin{abstract}
In order to provide probabilistic projections of the future evolution of the Atlantic Meridional Overturning Circulation (AMOC), we calibrated a simple Stommeltype box model to emulate the output of fully coupled threedimensional atmosphere-ocean general circulation models (AOGCMs) of the Coupled Model Intercomparison Project (CMIP). Based on this calibration to idealised global warming scenarios with and without interactive atmosphere-ocean fluxes and freshwater perturbation simulations, we project the future evolution of the AMOC mean strength within the covered calibration range for the lower two Representative Concentration Pathways (RCPs) until 2100 obtained from the reduced complexity carbon cycle-climate model MAGICC 6. For RCP3-PD with a global mean temperature median below $1.0^{\circ} \mathrm{C}$ warming relative to the year 2000 , we project an ensemble median weakening of up to $11 \%$ compared to $22 \%$ under RCP4.5 with a warming median up to $1.9^{\circ} \mathrm{C}$ over the 21 st century. Additional Greenland meltwater of 10 and $20 \mathrm{~cm}$ of global sea-level rise equivalent further weakens the AMOC by about 4.5 and $10 \%$, respectively. By combining our outcome with a multi-model sea-level rise study we project a dynamic sea-level rise along the New York City coastline of $4 \mathrm{~cm}$ for the RCP3-PD and of $8 \mathrm{~cm}$ for the RCP4.5 scenario over the 21 st century. We estimate the total steric and dynamic sea-level rise for New York City to be about $24 \mathrm{~cm}$ until 2100 for the RCP3-PD scenario, which can hold as a lower bound for sea-level rise projections in this region, as it does not include ice sheet and mountain glacier contributions.
\end{abstract}



Correspondence to: C. F. Schleussner (schleussner@pik-potsdam.de)

\section{Introduction}

The assessment of future risks of climate change requires not only mean projections but more importantly an estimate of the associated uncertainty ranges. Thus, probabilistic projections of climate systems for specific emission pathways are of great interest for the scientific community as well as for policy makers. Complex coupled Atmospheric-Ocean General Circulation Models (AOGCMs) are generally too computationally intensive to provide such probabilistic assessments with large ensembles of runs. This gap can be filled by models of reduced complexity that are able to emulate complex model output.

In this study we present such a reduced complexity model for the Atlantic Meridional Overturning Circulation (AMOC). One key component of this circulation is the formation of deepwater in the Nordic Seas and in the sub-polar North Atlantic that can be substantially hindered by a surface freshening in these regions. Anomalous freshwater flux into the North Atlantic has led to a shutdown of the circulation in a variety of coupled climate models (Rahmstorf et al., 2005). Furthermore, there is evidence that the AMOC has undergone abrupt changes during the last glacial period (McManus et al., 2004). A complete cessation of the circulation would cause strong cooling, reduced precipitation and substantial shifts of wind patterns in northern Europe (Vellinga and Wood, 2002, 2007; Laurian et al., 2009). Simulations further suggest that an AMOC collapse causes an increase of sea-level around European and North American coast lines by up to $1 \mathrm{~m}$ (Levermann et al., 2005; Landerer et al., 2007) and would have strong impacts on the ecosystem of the Atlantic Ocean (Schmittner, 2005). However, in the Fourth IPCC Assessment Report (AR4) none of the participating

Published by Copernicus Publications on behalf of the European Geosciences Union. 
models showed such an AMOC collapse in the 21st century, but all exhibited a weakening of the AMOC with a large ensemble spread (Meehl et al., 2007) ranging from almost no to a $50 \%$ reduction in volume flux. In view of this large uncertainty, an assessment of the impacts connected to a gradual decline of the AMOC in the 21 st century appears to be rather difficult.

Probabilistic projections of the AMOC behaviour under global warming scenarios have been performed in a number of different modelling experiments of different complexities (e.g. Challenor et al., 2006; Collins et al., 2006), mainly focussing on the risk of an abrupt cessation of the AMOC (Challenor et al., 2010; Hargreaves et al., 2004) and using observational data for historical constraining of the model parameters (Urban and Keller, 2010; Knutti et al., 2003).

Here, we present a different approach towards a probabilistic assessment of the uncertainty in mean AMOC projections by integrating three qualitatively different multi-model AOGCM emulation experiments. First, a simple conceptual model is used to emulate AOGCM simulations that provide an ideal setting for stepwise constraining the model parameters (Gregory et al., 2005; Stouffer et al., 2006). These calibrated emulators, or surrogates to be more explicit, are then forced with probabilistic projections of the global mean surface air temperature from the reduced complexity carbon cycle-climate model MAGICC6 (Meinshausen et al., 2011a,b). The combination of the obtained AMOC mean weakening projections with results of a multi-model sealevel rise study by Yin et al. (2009) finally allows for probabilistic projections for the dynamical sea-level rise in the New York City region.

In the second section of this manuscript we will introduce the conceptual AMOC model used in this study. The calibration of this model to AOGCM output is detailed in Sect. 3. As shown in Sect. 4 we calibrated our conceptual model to the output of five different AOGCMs. Using this calibrated emulator model we present probabilistic projections of the AMOC mean behaviour under two Representative Concentration Pathway emission scenarios RCP3-PD and RCP4.5 in Sect. 5. The influence of additional Greenland melting is investigated in Sect. 6. Projections for the dynamical sea-level rise in the New York City region are presented in Sect. 7, before some conclusions are drawn in Sect. 8.

\section{Model description}

In order to capture the basic physical processes relevant for the future AMOC evolution we use the box model by Stommel (1961). It incorporates the linear relation between volume transport and meridional density difference $m \propto \Delta \rho$ that has been reported in a number of coarse resolution ocean simulations under very different forcing scenarios (e.g. Hughes and Weaver, 1994; Klinger and Marotzke, 1999;

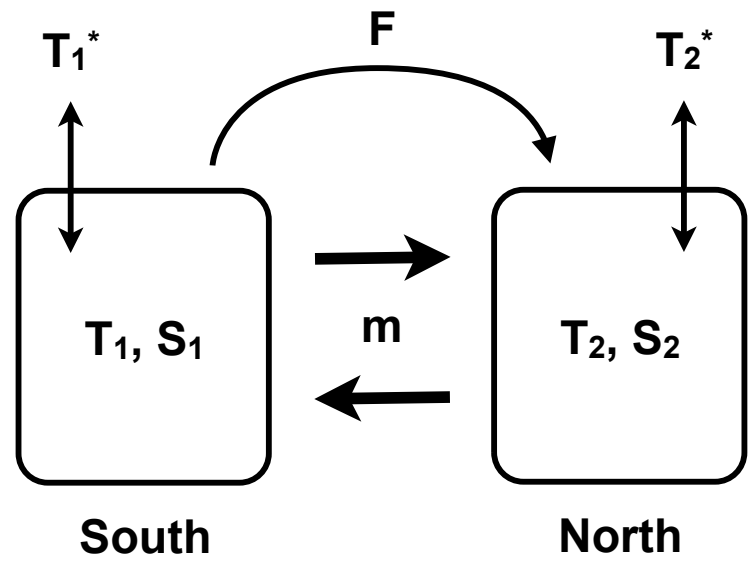

Fig. 1. Schematic view of our conceptual two box model for the Atlantic Meridional Overturning Circulation.

Griesel and Morales-Maqueda, 2006; Schewe and Levermann, 2010). The box model's simplicity further allows a calibration with a minimal number of free parameters. As we will show in Sect. 3, the design of a multi-model study on AMOC-stability presented in Gregory et al. (2005) and Stouffer et al. (2006) can be related to the free parameters in the Stommel model and thereby be used to constrain their values.

The Stommel model was used in a variety of studies investigating the stability of the AMOC (e.g. Rahmstorf, 1996; Dijkstra et al., 2004; Guan and Huang, 2008; Drijfhout et al., 2010) or combined socio-economical impacts (Zickfeld and Bruckner, 2008). It does, however, not account for other driving mechanisms of the AMOC (Kuhlbrodt et al., 2007) such as Southern Ocean winds (Toggweiler and Samuels, 1998). This clearly limits the applicability of the model, since it was recently shown that pycnocline dynamics such as those introduced by Gnanadesikan (1999) are necessary to capture the full AMOC dynamics in a coarse resolution model (Levermann and Fürst, 2010). Here, we argue that the box-model can nonetheless emulate mean AMOC behaviour far away from a potential threshold in capturing the firstorder baroclinic response to surface heat- and freshwater flux anomalies especially for time scales up to the year 2100 .

In our study we follow the emulation approach of Zickfeld et al. (2004), who applied a Stommel model as an emulator to an earth system model of intermediate complexity. In their study, however, they aimed to emulate the threshold behaviour of the AMOC and thus used long-term hysteresis experiments for their calibration. The model used in our study (Fig. 1) has two boxes, one northern box representing the deep convection regions in the North Atlantic north of $45^{\circ} \mathrm{N}$ and one comprising the tropical and southern Atlantic.

The meridional volume transport $m$ between the two boxes is determined by

$m=k[\beta \Delta S-\alpha \Delta T]$, 
where $k$ is a proportionality constant, which will be used to tune the box model to different AOGCMs, $\Delta S=S_{2}-$ $S_{1}$ being the salinity difference and $\Delta T=T_{2}-T_{1}$ being the temperature difference between the two boxes, $\alpha=1.7 \times 10^{-4} \mathrm{~K}^{-1}$ the thermal and $\beta=8 \times 10^{-4} \mathrm{psu}^{-1}$ the haline expansion coefficient. Atmospheric forcing via a freshwater transport between the boxes and a temperature coupling with the surrounding is applied. This approach results in a set of four ordinary differential equations:

$$
\begin{aligned}
& \dot{T}_{1}=\frac{m}{V_{1}}\left(T_{2}-T_{1}\right)+\lambda\left(T_{1}^{*}-T_{1}\right) \\
& \dot{T}_{2}=\frac{m}{V_{2}}\left(T_{1}-T_{2}\right)+\lambda\left(T_{2}^{*}-T_{2}\right) \\
& \dot{S}_{1}=\frac{m}{V_{1}}\left(S_{2}-S_{1}\right)+\frac{S_{0} F}{V_{1}} \\
& \dot{S}_{2}=\frac{m}{V_{2}}\left(S_{1}-S_{2}\right)-\frac{S_{0} F}{V_{2}},
\end{aligned}
$$

where $S_{0}=35 \mathrm{psu}$ is the reference salinity and $V_{1}$ and $V_{2}$ are the box volumes. $T_{1}^{*}$ and $T_{2}^{*}$ are reference temperatures in the absence of oceanic heat transport, representing the atmospheric thermal forcing of the ocean, $\lambda$ is the thermal coupling constant and $F$ the freshwater transport between the boxes that incorporates both atmospheric moisture transport and oceanic eddy and gyre circulation transport.

Just considering temperature and salinity differences between the northern and the southern box instead of absolute values, Eqs. (2)-(5) can be rewritten as

$$
\begin{aligned}
& \Delta \dot{T}=-m V_{\mathrm{eff}} \Delta T-\lambda \Delta T+\lambda \Delta T^{*} \\
& \Delta \dot{S}=-m V_{\mathrm{eff}} \Delta S-F S_{0} V_{\mathrm{eff}},
\end{aligned}
$$

where $V_{\text {eff }}$ is the effective volume $V_{\text {eff }}=\frac{V_{1}+V_{2}}{V_{1} V_{2}}$. Combining Eqs. (6) and (7) with Eq. (1) yields:

$$
\begin{aligned}
& \Delta \dot{T}=k \alpha V_{\mathrm{eff}}(\Delta T)^{2}-k \beta V_{\mathrm{eff}} \Delta T \Delta S-\lambda \Delta T+\lambda \Delta T^{*} \\
& \Delta \dot{S}=k \beta V_{\mathrm{eff}} \Delta T \Delta S-k \alpha V_{\mathrm{eff}}(\Delta S)^{2}-F S_{0} V_{\mathrm{eff}}
\end{aligned}
$$

As found for regional changes in surface air temperatures (e.g. Mitchell, 2003; Giorgi, 2008), we assume that our reference temperature difference scales linearly with $\delta T_{\text {glob: }}$ :

$$
\delta\left(\Delta T^{*}\right)=\Delta T_{0}^{*}+p \delta T_{\mathrm{glob}}
$$

where $p$ is the temperature forcing coefficient and $\Delta T_{0}^{*}$ the equilibrium temperature difference. Furthermore, we assume that the freshwater transport $F$ into the northern box can be approximated linearly (Manabe and Stouffer, 1994; Rahmstorf and Ganopolski, 1999) by introducing a model specific hydrological sensitivity $h$ :

$\delta F=F_{0}+h \delta T_{\mathrm{glob}}$.
Thus, the temporal evolution of AMOC strength $m$ can be expressed as a function of global mean temperature change $\delta T_{\text {glob. }}$. The equilibrium freshwater flux $F_{0}$ mainly influences the equilibrium overturning, which can ultimately be adjusted by the proportional constant $k$ (compare Eq. 1). We therefore set $F_{0}$ for all models to $0.014 \mathrm{~Sv}$ according to Zickfeld et al. (2004). Thus, the number of adjustable parameters is limited to six: $k, V_{\text {eff }}, \lambda, \Delta T_{0}^{*}, p$, and $h$. The calibration procedure of this set of parameters and the associated data sets are described in the following section.

\section{Calibration data}

In order to calibrate our conceptual model we use results from a related multi-model study on AMOC-stability presented in Gregory et al. (2005) and Stouffer et al. (2006). In the latter, an artificial freshwater flux of $0.1 \mathrm{~Sv}$ is applied for 100 years in the Northern North Atlantic and the transient weakening of the AMOC as well the recovery is modelled for 200 years. This type of experiment with a temporal external forcing is particularly suitable to calibrate our emulation model to initial climate conditions by tuning $k, V_{\text {eff }}, \lambda$, and $\Delta T_{0}^{*}$.

In Gregory et al. (2005) the transient impact of global warming on the AMOC is investigated. For this purpose, not only results of a $1 \% \mathrm{CO}_{2}$ quadrupling scenario are presented, but also the impacts of associated changes in heat flux and freshwater transport on the AMOC are investigated separately. Two additional transient experiments are performed in this study: one changing the atmospheric heat budget according to the warming scenario with freshwater fluxes prescribed to the control experiment and a second one which prescribes the freshwater fluxes as in the warming experiment but keeping $\mathrm{CO}_{2}$-concentrations and thus the heat fluxes constant. The constant freshwater flux experiment is used here to determine AOGCM-specific temperature scaling coefficient $p$ and the constant heat flux experiment to calibrate the hydrological sensitivity $h$. Finally, the fully combined transient run is used to validate our calibration as shown in Sect. 4.

The five AOGCMs that participated in both multi-model studies and that we used for our emulation approach are listed in Table 1. Also the HadCM3 AOGCM by the Hadley Centre for Climate Prediction and Research participated in both studies, but this model shows a large overshoot of the AMOC strength after recovery from the freshwater perturbation in Stouffer et al. (2006). This overshoot is dominated by a convective release of subsurface heat as reported in Mignot et al. (2007). Such changes in convection and the associated vertical thermal structure in the ocean can not be captured by the Stommel model, which is why we excluded the HadCM3 model from this study. 
Table 1. List of the emulated AOGCMs.

\begin{tabular}{lll}
\hline Model: & Institute & Reference \\
\hline GFDL_R30 & Geophysical Fluid Dynamics Laboratory, USA & Delworth et al. (2002) \\
MRI_CGCM2.3 & Meteorological Research Institute, Japan & Yukimoto and Noda (2002) \\
ECHAM5/MPI-OM & Max Planck Institute for Meteorology, Germany & Jungclaus et al. (2006a) \\
MIROC3.2 & University of Tokyo, Japan & Hasumi and Emori (2004) \\
NCAR_CCSM2.0 & National Center for Atmospheric Research,USA & Kiehl and Gent (2004) \\
\hline
\end{tabular}

\section{Calibration of the conceptual model to AOGCM overturning behaviour}

As discussed above, the equilibrium state of our simple model is determined by four parameters, $k, V_{\text {eff }}, \lambda$ and $\Delta T_{0}^{*}$. To calibrate this parameter-set to the AOGCM outputs, the same freshwater perturbation experiment as performed with the AOGCMs (see data Sect. 3) was computed with our emulation model and the parameter-set was adjusted to reproduce each AOGCM output (Table 2). The parameter adjustment was done by a visual comparison of model output and reference data. This allows to pay special attention on the reproduction of dynamical key elements such as the turning point or the saturation dynamic while neglecting superposed oscillation dynamics not covered by the model physics, which is difficult to achieve using automated numerical optimisation methods. It is important to note that the parameter-sets were validated independently with different sensitivity experiments as it will be shown below.

The AOGCM output (thin lines) and our emulated paths (thick lines) are presented in Fig. 2a. Starting values were taken from Zickfeld et al. (2004).The atmospheric coupling parameter $\lambda$ varies by more than one order of magnitude between the models (Table 2), which emphasises the dominant role of heat fluxes in the global warming experiments in line with Gregory et al. (2005). However, the parameter values $k$, $V_{\text {eff }}, \lambda$ and $\Delta T_{0}^{*}$ do not allow for more than a qualitative interpretation.

After the calibration to the equilibrium response the temperature scaling coefficient $p$ and the hydrological sensitivity $h$ are determined. In Gregory et al. (2005) the haline and thermal contributions to the AMOC weakening were separated, which can be used to independently determine the two parameters (Table 2). The thermal case, a scenario with a compounded $1 \%$ per year increase in the $\mathrm{CO}_{2}$ concentration with freshwater fluxes prescribed as in the control experiment, is shown in Fig. 2b. To determine the haline contribution the $\mathrm{CO}_{2}$-concentration is held constant and the timevarying freshwater flux of the warming scenario is applied (Fig. 2c). Please note that the NCAR CCSM2.0 model shows a nearly constant atmospheric freshwater transport and has therefore a near-zero hydrological sensitivity, which is captured by our emulation.
To test our calibrated conceptual models we emulated a compounded $1 \%$ per year $\mathrm{CO}_{2}$ concentration increase scenario and compared it with the reference experiment from Gregory et al. (2005). As shown in Fig. 3 our calibrated model outcome (thick line) is able to reproduce the AOGCM outcome (thin line) over the given time scale that corresponds to a warming below $3{ }^{\circ} \mathrm{C}$ in all models. We will use this calibrated emulation model in the next section to emulate low emission scenarios. This can be considered as an interpolation - we will not extrapolate to high emission scenarios, since these are not reached in the simulations used for the calibration and will push the system closer or beyond to the Stommel threshold. The Stommel equilibrium threshold is about $3{ }^{\circ} \mathrm{C}$ warming for our model ensemble.

As apparent in Fig. 2 AMOC behaviour differs strongly across the different emulated AOGCMs. The equilibrium AMOC strength ranges from $15 \mathrm{~Sv}$ for the ECHAM5/MPIOM model to $25 \mathrm{~Sv}$ for GFDL_R30 and also the transient response under the applied forcing differs significantly. Again the difference is highest between the GFDL_R30 model and the ECHAM5/MPI-OM: the first shows a strong weakening when additional freshwater forcing is applied and a rapid recovery afterwards, whereas the latter shows a much slower recovery that is not fully completed within the following 100 years. The uncertainty associated with single emulation parameters of the different models is thereby much smaller than the inter-AOGCM spread. Thus, we account for the major parametric uncertainty component when assuming all five emulator configurations obtained here as equally likely representations of the AMOC.

\section{Emulating the overturning under global warming scenarios}

In order to project the mean AMOC behaviour under global warming we combine each calibrated conceptual model (representing the AMOC behaviour of different AOGCMs) with the probabilistic temperature evolutions as obtained from an historically constrained MAGICC6 version (Meinshausen et al., 2009) for future RCP scenarios.

More specifically, we use 600 random drawings out of a 82-dimensional joint parameter distribution, randomly combined with 10 emulations of C4MIP carbon cycle response 



Fig. 2. The results of the calibration procedure, the thin line represents the AOGCM output, the thick line the best fit results of our emulation. (a) The freshwater hosing experiment by Stouffer et al. (2006), where $0.1 \mathrm{~Sv}$ are artificial added in the Northern North Atlantic for 100 years starting in year 1. (b) The transient change in the AMOC strength as presented in Gregory et al. (2005) for a scenario with a compounded $1 \%$ per year increase in the $\mathrm{CO}_{2}$ concentration, while the freshwater fluxes are kept constant. (c) The same scenario as in (b), but with constant $\mathrm{CO}_{2}$-concentrations, whereas the freshwater fluxes of the full transient scenario are applied.

characteristics (Friedlingstein et al., 2006), to project globalmean temperatures. Results for the harmonised emissions scenarios of RCP3-PD and RCP4.5 are shown in Fig. 4b. We then combine all 600 realisations with each of our five models leading to 3000 different AMOC mean pathways that are

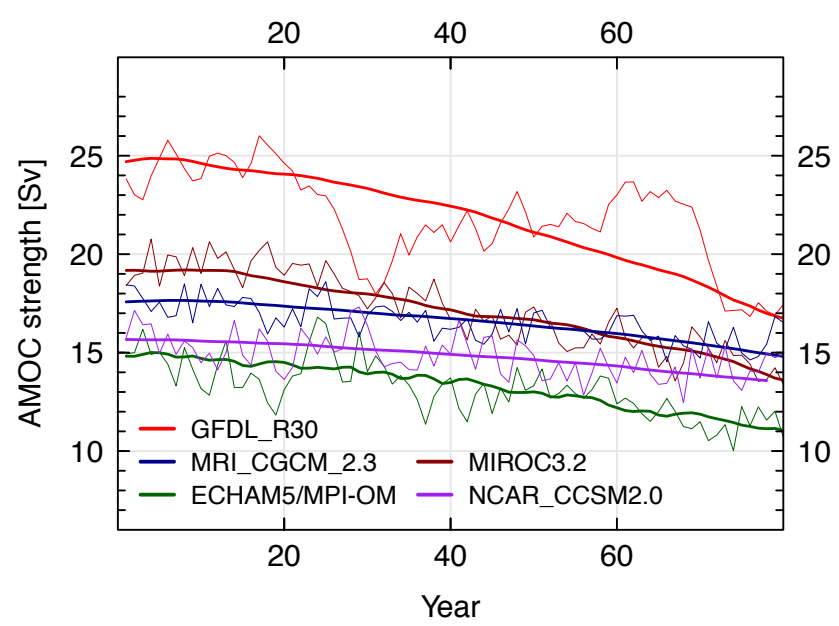

Fig. 3. Comparison of the calibrated model outcome (thick line) with the AOGCM reference data for the $1 \% \mathrm{CO}_{2}$ increase scenario from Gregory et al. (2005) (thin line). Our emulation outcome reproduces the weakening trend of all five AOGCMs.

Table 2. Results of the parameter optimisation. Values are given in: $k\left[10^{18} \mathrm{~m}^{3} \mathrm{a}^{-1}\right], V_{\text {eff }}\left[10^{-17} \mathrm{~m}^{3}\right], \lambda$ dimensionless, $\Delta T_{0}^{*}[\mathrm{~K}]$, $p$ dimensionless and $h\left[\mathrm{~Sv} \mathrm{~K}^{-1}\right]$.

\begin{tabular}{lrrrrr}
\hline & GFDL & MRI & MPI & MIROC & NCAR \\
\hline$k$ & 3.55 & 1 & 1.1 & 1.05 & 1.14 \\
$V_{\text {eff }}$ & 7.2 & 6 & 5 & 6 & 4.2 \\
$\lambda$ & 0.032 & 0.185 & 0.7 & 0.16 & 0.02 \\
$\Delta T_{0}^{*}$ & -3.8 & -4 & -2.75 & -4.3 & -5.5 \\
$p$ & 0.4 & 0.1 & 0.2 & 0.45 & 0.9 \\
$h$ & 0.019 & 0.038 & 0.013 & 0.013 & -0.003 \\
\hline
\end{tabular}

considered equally likely. In order to stay within the calibrated range of temperature and freshwater changes, we performed projections only for these low scenarios RCP3-PD and RCP4.5.

Even though the thermal and haline contributions are very different between the five different models (compare the temperature scaling coefficient $p$ and the hydrological sensitivity $h$ in Table 2), the relative AMOC reduction under global warming is similar. For the RCP3-PD scenario the ensemble median (Fig. 4a blue curve) shows a median weakening of about $11 \%$ with respect to the year 2000 with a $50 \%$ constrained range between 9 and $14 \%$. Note that this constrained range comprises the uncertainty in the temperature projections and the ensemble spread. The RCP4.5 scenario results in a stronger weakening of about $22 \%$ in the five model ensemble (Fig. $4 \mathrm{~b}$ red curve) with a $50 \%$ constrained range between 18 and $24 \%$. The inter-AOGCM spread for the RCP4.5 scenario is about $6 \%$ (compare Fig. S1 in the Supplement), which is the major uncertainty component 

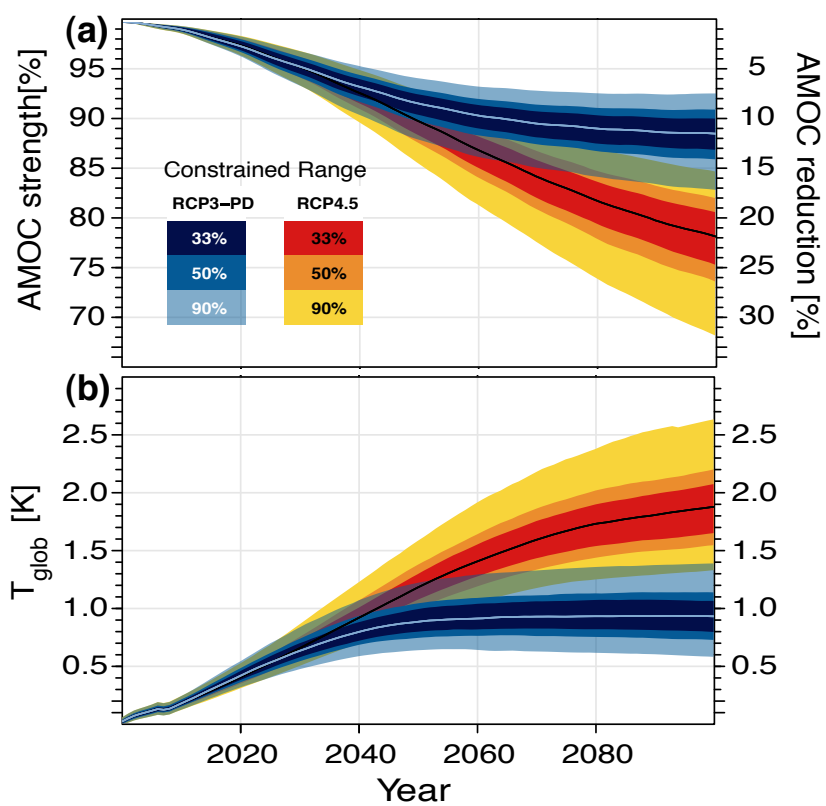

Fig. 4. Probabilistic future projections for the RCP3-PD and RCP4.5 scenario relative to the year 2000: (a) AMOC based on the equally weighted five model ensemble (individual model projections are shown in Fig. S1 of the Supplement). (b) Corresponding global mean temperature obtained from the MAGICC6 model emulating IPCC AR-4 models.

compared to the uncertainty of the individual model parameters. Our results are in very good agreement with a historical constrained Bayesian model study by Urban and Keller (2010), where a weakening of $17 \%$ is projected for a 21 st century warming of $1.5 \mathrm{~K}$.

\section{Accounting for meltwater influx from Greenland}

The AOGCM simulations of the $\mathrm{CO}_{2}$ quadrupling scenario used for calibration do not account for possible meltwater run-off from Greenland, but since we calibrated our model with absolute freshwater fluxes (see the calibration Sect. 4), we can now additionally investigate the effect of Greenland melting on the AMOC within the calibrated range of our model. The amount of Greenland meltwater run-off is one of the major sources of uncertainty e.g. in projections of global sea-level rise until 2100 (Gregory and Huybrechts, 2006). In particular the role of outlet glacier melting remains unclear. Recent findings suggest a strong acceleration of this melting in Southern Greenland (e.g. Rignot et al., 2010, and references therein). Pfeffer et al. (2008) assessed the maximum ice discharge from Greenland through kinematic constraints. In their assessment the total Greenland contribution by 2100 is projected to be $16.5 \mathrm{~cm}$ for low-range sea-level rise (SLR) scenarios, for which they assume a doubling in the Greenland outlet glacier velocities within the next decade.

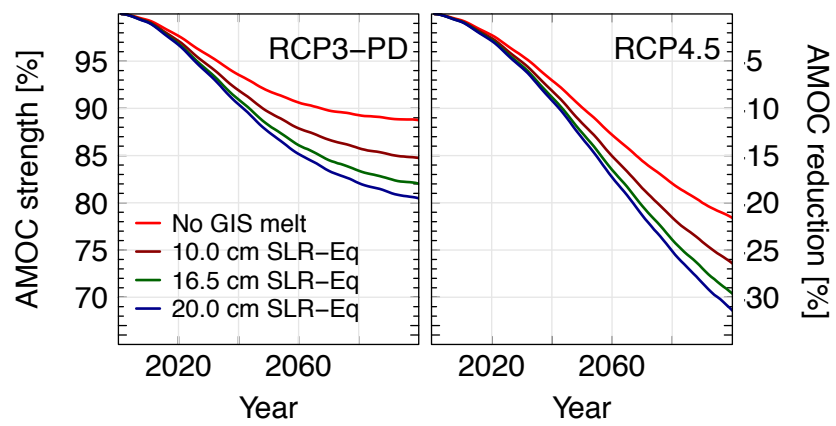

Fig. 5. Projections of the probabilistic ensemble median AMOCreduction for different Greenland meltwater influx scenarios for the RCP3-PD (left panel) and the RCP4.5 (right panel) emission pathway. Additional freshwater forcings correspond to 10, 16.5 and $20 \mathrm{~cm}$ Greenland contribution to global SLR by 2100 .

Graversen et al. (2010) found $17 \mathrm{~cm}$ to be an upper bound using a dynamical ice-sheet model. Given these estimates we applied an additional freshwater forcing corresponding to a contribution of Greenland to global sea-level rise by 2100 of $10,16.5$ and $20 \mathrm{~cm}$. Following Rahmstorf and Ganopolski (1999) we assumed a linear increase in the meltwater flux with global mean temperature change, which results in maximum freshwater fluxes of $14 \mathrm{mSv}, 23 \mathrm{mSv}$ and $28 \mathrm{mSv}$ for the different SLR-contributions between 2090 and 2100.

Figure 5 shows the probabilistic projected ensemble medians for the RCP3-PD (left) and RCP4.5 (right) emission scenarios and the different Greenland freshwater forcings. The additional weakening with regard to the control run (red curve) is similar for both emission scenarios ( $4 \%$ and $9 \%$ for RCP3-PD and $4.5 \%$ and $10 \%$ for RCP4.5 and 10 and $20 \mathrm{~cm}$, respectively), even though the absolute AMOC weakening is much stronger in the RCP4.5 scenario. Similar experiments have been performed by Jungclaus et al. (2006b), who found an additional AMOC weakening of $5 \%$ by 2100 for the A1B emission scenario and $10 \mathrm{~cm}$ SLR contribution in the ECHAM5/MPI-OM AOGCM.

Despite this good agreement, we would like to highlight the conceptual nature of our experiment. In reality the Greenland meltwater flux is of course not uniformly applied over the whole northern North Atlantic and therefore the interaction with horizontal circulations can not be neglected (Jungclaus et al., 2006b). Recent findings even suggest that the subpolar gyre in the North Atlantic shows strong nonlinear behaviour with regard to regional freshwater forcings (Levermann and Born, 2007), probably influencing the AMOC behaviour (Montoya et al., 2010). 


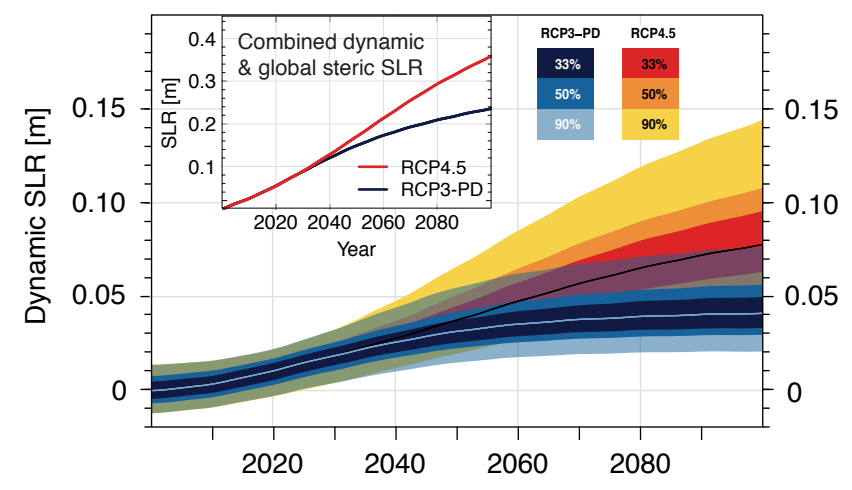

Fig. 6. Probabilistic projections of the mean dynamic sea-level rise at the New York City coastline for the RCP3-PD (blue) and the RCP4.5 (orange) emission pathway until 2100. We project a median dynamic sea-level rise of $4 \mathrm{~cm}$ for the RCP3-PD and $8 \mathrm{~cm}$ for the RCP4.5 scenario. Inlay: Estimates of the steric and dynamic sea-level rise at the New York City coastline by combining our projections with simulations of the global steric sea-level rise by Schewe et al. (2011).

\section{Projections of dynamic sea-level rise along the east coast of North America}

Associated with an AMOC weakening are major changes in the sea-level patterns in the Atlantic, particularly a distinct rise in the North Atlantic (Levermann et al., 2005). While dynamic sea-level rise (SLR) is not spatially uniform and and might be even negative in the subpolar gyre region (Landerer et al., 2007), it is robustly projected to be especially pronounced at the north-eastern coast of North America over an ensemble of the 12 AR4 models that perform best reproducing present-day sea-level (Yin et al., 2010). Furthermore, Yin et al. (2009) report a linear dependence of the dynamic sealevel rise (DSLR) in the New York City region on the AMOC weakening and here we utilize this finding to provide probabalistic projections of this rise. The CMIP-3 model ensemble analysed in this study and associated linear regression results are shown in Table 3. The slopes of the different models scatter around $2 \mathrm{~cm}$ DSLR per Sv AMOC weakening, which compares well to observational data (Bingham and Hughes, 2009).

To account for the uncertainty of the linear regression parameters shown in Table 3, we randomly picked a value out of a Gaussian distribution with a standard deviation of the parameter uncertainty and combined it for each of the five models with our 3000 AMOC representations. Thus, we provide probabilistic projections of the mean dynamic sea-level rise in the New York City region (Fig. 6).

While Greenland melting will have significant effect on global sea-level, its impact on regional sea-level along the North American east coast has been shown to be small due to gravitational and rotational adjustments (Mitrovica et al., 2001; Kopp et al., 2010). Thus, Fig. 6 represents an estimate
Table 3. Results of a linear regression of DSLR vs. AMOC weakening $(y=a x+b)$ for a AR4 model ensemble derived from SRES A1B scenario runs and for the grid-point closest to NYC from (Yin et al., 2009)

\begin{tabular}{lcc}
\hline & $a\left[\mathrm{~cm} \mathrm{~Sv}^{-1}\right]$ & $b[\mathrm{~cm}]$ \\
\hline GFDL CM2.1 & $1.68 \pm 0.08$ & $3.30 \pm 0.56$ \\
MIROC MEDRES & $2.81 \pm 0.14$ & $1.95 \pm 0.62$ \\
MPI ECHAM5 & $2.74 \pm 0.26$ & $2.63 \pm 0.65$ \\
IPSL CM4 & $2.58 \pm 0.15$ & $2.32 \pm 0.67$ \\
MIROC HIRES & $1.45 \pm 0.21$ & $4.01 \pm 0.59$ \\
\hline
\end{tabular}

of the full sea-level change in the area due to non-tectonic effects excluding contributions from Antarctica. We find a median DSLR of $4 \mathrm{~cm}$ for the RCP3-PD and $8 \mathrm{~cm}$ for the RCP4.5 scenario with a $50 \%$ confined range of 2.8 to 5.7 and 5 to $11 \mathrm{~cm}$, respectively. While the initial spread of $\pm 0.5 \mathrm{~cm}$ reflects the uncertainty of the offset parameter $b$, the 2100 ranges are dominated by the inter-AOGCM spread with AOGCM specific parameter uncertainties being of minor importance. For the higher SRES A1B scenario Yin et al. (2009) report an AMOC slow-down of $41 \%$ for the GFDL CM2.1 and a multi-model median dynamic sea-level rise of about $20 \mathrm{~cm}$.

\section{Conclusions}

In this paper we expanded the idea of emulating complex model output by computationally efficient models of low complexity to the Atlantic Meridional Overturning Circulation and its behaviour under moderate global warming. In a conceptual approach we used a Stommel model consisting of two boxes and a simple atmospheric coupling to emulate AMOC dynamics. The transient model behaviour can be calibrated by a set of six parameters including hydrological sensitivity and a temperature scaling coefficient to account for changes in the atmospheric forcing in terms of global mean temperature change. We calibrated different versions of our conceptual model to represent the outcome of five AOGCMs that participated in the multi-model studies by Stouffer et al. (2006) and Gregory et al. (2005) and performed probabilistic projections of the AMOC slow-down by 2100 using probabilistic projections of the global mean temperature change for the RCP3-PD and the RCP4.5 emission pathways obtained by MAGICC6. In the five model ensemble median the AMOC weakened by $11 \%$ for the RCP3-PD and by $22 \%$ for the RCP4.5 scenario.

The calibration of our emulation models to AOGCM data was successful for the documented range until 2100 and low emission scenarios. However, there are numerous limitations of our simple model. Since we assumed a purely density driven AMOC with a volume transport that scales linearly 
with the density gradient between the boxes, the Stommel box model shows a bistability with regard to freshwater forcing and strong nonlinear behaviour close to the bifurcation point that can not be identified in the AOGCM output data.

The conceptual model omits low latitude upwelling and southern ocean winds as important drivers of the AMOC (Toggweiler and Samuels, 1995). Including them leads to a much more complex dependence of the meridional volume transport on the density gradient (Levermann and Fürst, 2010), but could help to extend our approach also to high emission - high warming scenarios (Fürst and Levermann, 2012). This model limitation does not effect the results presented in this work, since all projections performed are interpolations inside the calibration range.

Our calibration to absolute freshwater fluxes allowed us to investigate the impact of meltwater fluxes from Greenland on the AMOC, an aspect not included in the reference AOGCM experiments. We performed probabilistic projections for three different freshwater forcings that would correspond to $10,16.5$ and $20 \mathrm{~cm}$ Greenland contribution to SLR by 2100 and found additional reductions of the AMOC strength of 4, 7.5 and $9 \%$ for the RCP3-PD scenario and slightly higher for the RCP4.5. Being aware of the limitations of these projections that do not account for the dynamics of the horizontal circulation in the North Atlantic, they can nevertheless hold as a first estimate of the effect of Greenland melting on the AMOC until the end of the century.

Using a multi-model sea-level rise study by Yin et al. (2009), we were able to extend our probabilistic projections to investigate the impact of the AMOC slow-down on the dynamic sea-level rise in the New York City region as an example of an impact assessment. We find $4 \mathrm{~cm}$ of dynamic sea-level rise for the RCP3-PD and $8 \mathrm{~cm}$ for the RCP4.5 scenario. This probabilistic projection of dynamic sea-level rise is an example for the potential of a modular approach in climate system projections within the limits of interpolation. Simulations performed with a climate model of intermediate complexity show a global steric sea-level rise in the $21 \mathrm{st}$ century of about $20 \mathrm{~cm}$ for the RCP3-PD and $28 \mathrm{~cm}$ for the RCP4.5 emission pathway with regard to the year 2000 (Schewe et al., 2011), which is close to the upper $95 \%$ percentile provided in IPCC AR4 for the similar SRES B1 scenario (Meehl et al., 2007). These numbers combine to a dynamic and steric sea-level rise of 24 and $36 \mathrm{~cm}$ in the New York City region (Fig. 6, inlay).

Remarkably, the combined steric and dynamic sea-level rise decelerates already in the 21 st century for the lowest emission pathway RCP3-PD (compare Fig. 6, inlay), which is consistent with the evolution of the global mean temperature that reaches its maximum around 2060 (Fig. 4b). Nevertheless, sea-level responds slowly to global warming and continues to rise until the 23rd century for this emission pathway (Schewe et al., 2011).

In summary, we presented a probabilistic assessment of the future AMOC behaviour using a calibrated conceptual model and global mean temperature data for the RCP3-PD and RCP4.5 emission scenarios. Additionally, we extended our modular approach to investigate the influence of Greenland meltwater fluxes on the AMOC and to project dynamic sea-level rise in the New York City region. Our finding of $24 \mathrm{~cm}$ combined dynamic and steric sea-level rise for the RCP3-PD emission pathway can be interpreted as a lower bound for the total sea-level rise at the New York City coastline until 2100.

\section{Supplementary material related to this article is available online at: http://www.earth-syst-dynam.net/2/191/2011/ esd-2-191-2011-supplement.pdf.}

Acknowledgements. We wish to thank Sarah Raper and Jonathan Gregory, who kindly provided the data-sets used to calibrate our emulation models. This work was supported by the Deutsche Bundesstiftung Umwelt and the German National Academic Foundation. M. M. and K. F. were supported by the Federal Environment Agency for Germany (UBA) under project UFOPLAN FKZ 370841103.

Edited by: K. Keller

\section{References}

Bingham, R. J. and Hughes, C. W.: Signature of the Atlantic meridional overturning circulation in sea level along the east coast of North America, Geophys. Res. Lett., 36, L02603, doi:10.1029/2008GL036215, 2009.

Challenor, P. G., Hankin, R. K. S., and Marsh, R.: Towards the probability of rapid climate change, Avoiding dangerous climate change, Cambridge Univ. Pr, 55-63, 2006.

Challenor, P., McNeall, D., and Gattiker, J.: Assessing the probability of rare climate events, The Oxford handbook of applied Bayesian analysis, Oxford Univ. Pr., 403-430, 2010.

Collins, M., Booth, B. B. B., Harris, G. R., Murphy, J. M.,Sexton, D. M. H., and Webb, M. J.: Towards quantifying uncertainty in transient climate change, Clim. Dynam., 27, 127-147, 2006.

Delworth, T., Stouffer, R., Dixon, K., Spelman, M., Knutson, T., Broccoli, A., Kushner, P., and Wetherald, R.: Review of simulations of climate variability and change with the GFDL R30 coupled climate model, Clim. Dynam., 19, 555-574, 2002.

Dijkstra, H., Raa, L., and Weijer, W.: A systematic approach to determine thresholds of the ocean's Thermohaline circulation, Tellus A, 56, 362-370, 2004.

Drijfhout, S. S., Weber, S. L., and van der Swaluw, E.: The stability of the MOC as diagnosed from model projections for pre-industrial, present and future climates, Clim. Dynam., doi:10.1007/s00382-010-0930-z, in press, 2010.

Friedlingstein, P., Cox, P., Betts, R., Bopp, L., von Bloh, W., Brovkin, V., Cadule, P., Doney, S., Eby, M., Fung, I., Bala, G., John, J., Jones, C., Joos, F., Kato, T., Kawamiya, M., Knorr, W., Lindsay, K., Matthews, H., Raddatz, T., Rayner, P., Reick, C., Roeckner, E., Schnitzler, K.-G., Schnur, R., Strassmann, K., Weaver, K., Yoshikawa, C., and Zeng, N.: Climate Carbon Cycle 
Feedback Analysis: Results from the C4MIP Model Intercomparison, J. Climate, 19, 3337-3353, 2006.

Fürst, J., Levermann, A.: A minimal model for wind- and mixingdriven overturning - threshold behaviour for both driving mechanisms, Clim. Dynam., doi:10.1007/s00382-011-1003-7, in press, 2011.

Giorgi, F.: A simple equation for regional climate change and associated uncertainty, J. Climate, 21, 1589-1604, 2008.

Gnanadesikan, A.: A simple predictive model for the structure of the oceanic pycnocline, Science, 283, 2077-2079, 1999.

Graversen, R. G., Drijfhout, S., Hazeleger, W., Wal, R., Bintanja, R., and Helsen, M.: Greenland's contribution to global sea-level rise by the end of the 21 st century, Clim. Dynam., doi:10.1007/s00382-010-0918-8, in press, 2010.

Gregory, J. M. and Huybrechts, P.: Ice-sheet contributions to future sea-level change, Philos. T. Roy. Soc. A, 364, 1709-1731, 2006.

Gregory, J. M., Dixon, K. W., Stouffer, R. J., Weaver, A. J., Driesschaert, E., Eby, M., Fichefet, T., Hasumi, H., Hu, A., Jungclaus, J. H., Kamenkovich, I. V., Levermann, A., Montoya, M., Murakami, S., Nawrath, S., Oka, A., Sokolov, A. P., and Thorpe, R. B.: A model intercomparison of changes in the Atlantic thermohaline circulation in response to increasing atmospheric $\mathrm{CO}_{2}$ concentration, Geophys. Res. Lett., 32, L12703, doi:10.1029/2005GL023209, 2005.

Griesel, A. and Morales-Maqueda, M. A.: The relation of meridional pressure gradients to North Atlantic Deep Water volume transport in an OGCM, Clim. Dynam., 26, 781-799, 2006.

Guan, Y. P. and Huang, R. X.: Stommel's Box Model of Thermocline Circulation Revisited - The Role of Mechanical Energy Supporting Mixing and the Wind-Driven Gyration, J. Phys. Oceanogr., 38, 909-917, 2008.

Hargreaves, J. C., Annan, J. D., Edwards, N. R., and Marsh, R.: An efficient climate forecasting method using an intermediate complexity Earth System Model and the ensemble Kalman filter, Cim. Dynam., 23, 745-760, 2004.

Hasumi, H. and Emori, S.: K-1 coupled model (MIROC) description, Center for Climate System Research, University of Tokyo, K-1 Tech. Rep., 1, 34, 2004.

Hughes, T. M. C. and Weaver, A. J.: Multiple Equilibria of an Asymmetric Two-Basin Ocean Model, J. Phys. Oceanogr., 24, 619-637, 1994.

Jungclaus, J. H., Botzet, M., Haak, H., Marotzke, J., Mikolajewicz, U., Roeckner, E., Keenlyside, N., Latif, M., and Luo, J. J.: Ocean circulation and tropical variability in the coupled model ECHAM5/MPI-OM, J. Climate, 19, 3952-3972, 2006 a.

Jungclaus, J. H., Haak, H., Esch, M., Roeckner, E., and Marotzke, J.: Will Greenland melting halt the thermohaline circulation?, Geophys. Res. Lett., 33, L17708, doi:10.1029/2006GL026815, 2006b.

Kiehl, J. and Gent, P.: The community climate system model, version 2, J. Climate, 17, 3666-3682, 2004.

Klinger, B. A. and Marotzke, J.: Behavior of Double-Hemisphere Thermohaline Flows in a Single Basin, J. Phys. Oceanogr., 29, 382-399, 1999.

Knutti, R., Stocker, T. F., Joos, F., and Plattner, G. K.: Probabilistic climate change projections using neural networks, Clim. Dynam., 21, 257-272, 2003.
Kopp, R. E., Mitrovica, J. X., Griffies, S. M., Yin, J., Hay, C. C., and Stouffer, R. J.: The impact of Greenland melt on local sea levels: a partially coupled analysis of dynamic and static equilibrium effects in idealized water-hosing experiments, Climatic Change, 103, 619-625, 2010.

Kuhlbrodt, T., Griesel, A., Montoya, M., Levermann, A., Hofmann, M., and Rahmstorf, S.: On the driving processes of the Atlantic meridional overturning circulation, Rev. Geophys., 45, RG2001, doi:10.1029/2004RG000166, 2007.

Landerer, F. W., Jungclaus, J. H., and Marotzke, J.: Regional Dynamic and Steric Sea Level Change in Response to the IPCCA1B Scenario, J. Phys. Oceanogr., 37, 296-312, 2007.

Laurian, A., Drijfhout, S. S., Hazeleger, W., and Hurk, B.: Response of the Western European climate to a collapse of the thermohaline circulation, Clim. Dynam., 34, 689-697, 2009.

Levermann, A. and Born, A.: Bistability of the subpolar gyre in a coarse resolution climate model, Geophys. Res. Lett., 34, L24605, doi:10.1029/2007GL031732, 2007.

Levermann, A. and Fürst, J.: Atlantic pycnocline theory scrutinized using a coupled climate model, Geophys. Res. Lett., 37, L14602, doi:10.1029/2010GL044180, 2010.

Levermann, A., Griesel, A., Hofmann, M., Montoya, M., and Rahmstorf, S.: Dynamic sea level changes following changes in the thermohaline circulation, Clim. Dynam., 24, 347-354, 2005.

Manabe, S. and Stouffer, R. J.: Multiple-century response of a coupled ocean-atmosphere mocel to an increase of atmospheric carbon dioxide, J. Climate, 7, 5-23, 1994.

McManus, J. F., Francois, R., Gherardi, J. M., Keigwin, L. D., and Brown-Leger, S.: Collapse and rapid resumption of Atlantic meridional circulation linked to deglacial climate changes, Nature, 428, 834-837, 2004.

Meehl, G. A., Stocker, T. F., Collins, W. D., Friedlingstein, P., Gaye, A. T., Gregory, J. M., Kitoh, A., Knutti, R., Murphy, J. M., Noda, A., Raper, S. C. B., Watterson, I. G., Weaver, A. J., and Zhao, Z.C.: Climate Change 2007: The Physical Science Basis, Contribution of Working Group I to the Fourth Assessment Report of the Intergovernmental Panel on Climate Change, chap. Global Climate Projections, Cambridge University Press, Cambridge, UK and New York, NY, USA, 2007.

Meinshausen, M., Meinshausen, N., Hare, W., Raper, S. C. B., Frieler, K., Knutti, R., Frame, D. J., and Allen, M. R.: Greenhouse-gas emission targets for limiting global warming to $2{ }^{\circ} \mathrm{C}$, Nature, 458, 1158-1162, 2009.

Meinshausen, M., Raper, S. C. B., and Wigley, T. M. L.: Emulating coupled atmosphere-ocean and carbon cycle models with a simpler model, MAGICC6 - Part 1: Model description and calibration, Atmos. Chem. Phys., 11, 1417-1456, doi:10.5194/acp11-1417-2011, 2011a.

Meinshausen, M., Wigley, T. M. L., and Raper, S. C. B.: Emulating atmosphere-ocean and carbon cycle models with a simpler model, MAGICC6 - Part 2: Applications, Atmos. Chem. Phys., 11, 1457-1471, doi:10.5194/acp-11-1457-2011, 2011 b.

Mignot, J., Ganopolski, A., and Levermann, A.: Atlantic subsurface temperatures: response to a shut-down of the overturning circulation and consequences for its recovery, J. Climate, 20, 48844898, 2007. 
Mitchell, T.: Pattern scaling: an examination of the accuracy of the technique for describing future climates, Climatic Change, 60, 217-242, 2003.

Mitrovica, J. X., Tamisiea, M. E., Davis, J. L., and Milne, G. A.: Recent mass balance of polar ice sheets inferred from patterns of global sea-level change, Nature, 409, 1026-1029, 2001.

Montoya, M., Born, A., and Levermann, A.: Reversed North Atlantic gyre dynamics in present and glacial climates, Clim. Dynam., 36, 1107-1118, doi:10.1007/s00382-009-0729-y, 2010.

Pfeffer, W. T., Harper, J. T., and O’Neel, S.: Kinematic Constraints on Glacier Contributions to 21st-Century Sea-Level Rise, Science, 321, 1340-1343, 2008.

Rahmstorf, S.: On the freshwater forcing and transport of the Atlantic thermohaline circulation, Clim. Dynam., 12, 799-811, 1996.

Rahmstorf, S. and Ganopolski, A.: Long-term global warming scenarios computed with an efficient coupled climate model, Climatic Change, 43, 353, 1999.

Rahmstorf, S., Crucifix, M., Ganopolski, A., Goosse, H., Kamenkovich, I., Knutti, R., Lohmann, G., Marsh, B., Mysak, L. A., Wang, Z., and Weaver, A.: Thermohaline circulation hysteresis: A model intercomparison, Geophys. Res. Lett., 32, L23605, doi:10.1029/2005GL023655, 2005.

Rignot, E., Koppes, M., and Velicogna, I.: Rapid submarine melting of the calving faces of West Greenland glaciers, Nat. Geosci., 3, 187-191, 2010.

Schewe, J. and Levermann, A.: The role of meridional density differences for a wind-driven overturning circulation, Clim. Dynam., 34, 547-556, 2010.

Schewe, J., Levermann, A., and Meinshausen, M.: Climate change under a scenario near $1.5^{\circ} \mathrm{C}$ of global warming: monsoon intensification, ocean warming and steric sea level rise, Earth Syst. Dynam., 2, 25-35, doi:10.5194/esd-2-25-2011, 2011.

Schmittner, A.: Decline of the marine ecosystem caused by a reduction in the Atlantic overturning circulation, Nature, 434, 628633, 2005

Stommel, H.: Thermohaline convection with two stable regimes of flow, Tellus, 13, 224-230, 1961.

Stouffer, R. J., Yin, J., Gregory, J. M., Dixon, K. W., Spelman, M. J., Hurlin, W., Weaver, A. J., Eby, M., Flato, G. M., Hasumi, H., Hu, A., Jungclaus, J. H., Kamenkovich, I. V., Levermann, A., Montoya, M., Murakami, S., Nawrath, S., Oka, A., Peltier, W. R., Robitaille, D. Y., Sokolov, A. P., Vettoretti, G., and Weber, S. L.: Investigating the Causes of the Response of the Thermohaline Circulation to Past and Future Climate Changes, J. Climate, 19, 1365-1387, 2006.
Toggweiler, J. R. and Samuels, B.: Effect of Drake Passage on the global thermohaline circulation, Deep-Sea Res., 42, 477-500, 1995.

Toggweiler, J. R. and Samuels, B.: On the ocean's large scale circulation in the limit of no vertical mixing, J. Phys. Oceanogr., 28, 1832-1852, 1998.

Urban, N. M. and Keller, K.: Probabilistic hindcasts and projections of the coupled climate, carbon cycle, and Atlantic meridional overturning circulation system: A Bayesian fusion of centuryscale observations with a simple model, Tellus A, 62, 737-750, 2010

Vellinga, M. and Wood, R. A.: Global climatic impacts of a collapse of the Atlantic Thermohaline Circulation, Climatic Change, 54, 251-267, 2002.

Vellinga, M. and Wood, R. A.: Impacts of thermohaline circulation shutdown in the twenty-first century, Climatic Change, 91, 4363, 2007.

Yin, J., Schlesinger, M. E., and Stouffer, R. J.: Model projections of rapid sea-level rise on the northeast coast of the United States, Nat. Geosci., 2, 262-266, 2009.

Yin, J., Griffies, S., and Stouffer, R. J.: Spatial Variability of Sea Level Rise in Twenty-First Century Projections, J. Climate, 23, 4585-4607, 2010.

Yukimoto, S. and Noda, A.: Improvements of the Meteorological Research Institute global ocean-atmosphere coupled GCM (MRI-CGCM2) and its climate sensitivity, CGER's Supercomputer Activity Rep., Vol. 10, National Institute for Environmental Studies, Tsukuba, Japan, 37-44, 2002.

Zickfeld, K. and Bruckner, T.: Reducing the risk of Atlantic thermohaline circulation collapse: sensitivity analysis of emissions corridors, Climatic Change, 91, 291-315, 2008.

Zickfeld, K., Slawig, T., and Rahmstorf, S.: A low-order model for the response of the Atlantic thermohaline circulation to climate change, Ocean Dynam., 54, 8-26, 2004. 